\title{
Influencing the Properties of the Generated Surface by Adjusted Rake and Clearance Angles in Side Milling of Aluminum Matrix Composites with MCD-Tipped Tools
}

\author{
Benjamin Clauß ${ }^{1, * \mathbb{C}}$, Andreas Nestler ${ }^{1}{ }^{(\mathbb{D}}$, Andreas Schubert ${ }^{1}$,, Dagmar Dietrich $^{2}$ \\ and Thomas Lampke ${ }^{2}$ (D) \\ 1 Professorship Micromanufacturing Technology, Chemnitz University of Technology, Reichenhainer Str. 70, \\ 09126 Chemnitz, Germany \\ 2 Professorship of Materials and Surface Engineering, Chemnitz University of Technology, Erfenschlager \\ Str. 73, 09125 Chemnitz, Germany \\ * Correspondence: benjamin.clauss@mb.tu-chemnitz.de; Tel.: +49-371-531-33173
}

Received: 28 May 2019; Accepted: 17 July 2019; Published: 23 July 2019

\begin{abstract}
The application of aluminum matrix composites (AMCs) allows the reduction of moving loads for increased efficiency in modern technical systems. However, the presence of reinforcing particles leads to challenges in machining of AMCs, typically requiring diamond cutting materials. Single-edged MCD-tipped tools are used to investigate the influence of different clearance and rake angles on the resulting surface properties in milling, while the cutting parameters are kept constant. The specimens are manufactured from an aluminum wrought alloy comparable to EN AW-2017, reinforced with $10 \mathrm{vol} . \%$ of $\mathrm{SiC}$ particles. The surface properties are evaluated considering the surface structure, the residual stress state, and the microstructure of the surface layer. A clearance angle of the minor cutting edge of about $3^{\circ}$ on average leads to the lowest $R z$ values and a reduced fluctuation of surface roughness values. Using a tool with a positive rake angle of $5^{\circ}$ entails the highest absolute values of the compressive residual stresses and an increase compared to the initial state of up to about $290 \%$. The results contribute to an understanding of the relations between tool geometry and the generated surface properties required for a targeted enhancement of the functional performance when machining AMCs.
\end{abstract}

Keywords: aluminum matrix composite; clearance angle; MCD; milling; rake angle; residual stress state; surface integrity; surface layer; surface properties; surface structure

\section{Introduction}

\subsection{Technical and Economic Significance of AMCs}

Regarding technical systems, there is an increasing demand for efficiency. In this context, not only economic but also ecological aspects are brought into focus. One strategy in trying to meet the ever-stricter performance and efficiency criteria is seen in the reduction of moving loads.

This can be achieved for example by applying suitable lightweight designs. In addition to structural and integral design approaches, the application of high-strength lightweight materials is feasible. Metal matrix composites (MMCs) represent one group of these materials.

Kainer emphasized the importance of MMCs for lightweight applications and addressed aspects of MMC development such as manufacturing, machining, and characterization. According to the status in 2006 Kainer derives some challenges due to insufficient process stability in manufacturing 
processes and increased expenses hindering a wide usage in cost-oriented sectors such as transportation. Accordingly, MMCs are classified at an early stage of evolution as modern lightweight materials [1].

In addition, the research of Akhil presented trends and developments in MMC application as of the state in 2018. Significant advances in the fields of manufacturing and processing of MMCs are attested leading to reduced costs, improved material properties, and enhanced performance. Regarding numerous applications in automotive, aerospace, and others the paper projects a $20 \%$ increase of MMC-usage until 2020 [2].

Singh, Chaitanya, and Kumar stated that increased specific strength and the improved behavior at elevated temperatures explain the high relevance of MMCs as lightweight materials. In this context, the relevance of aluminum and titanium alloys as matrix materials is pointed out. $\mathrm{SiC}$ or $\mathrm{Al}_{2} \mathrm{O}_{3}$ particle-reinforced AMCs would provide higher isotropy compared to fiber-reinforced materials, thus being researched more extensively [3].

Schmidt et al. investigated the market potentials of powder metallurgically produced AMCs as substitute for an unreinforced aluminum alloy in aerospace industry identifying a significant market potential of Airbus and Boeing of about $\$ 160$ billion in 2016. The necessity of appropriate AMC machining solutions is pointed out as a key component for a successful transfer into industrial applications [4].

In addition to the enhancement of material properties, sustainable engineering, and the possibilities of an efficient recuperation of resources are increasingly brought into focus.

Guo, Liu, and Shu investigated the material characteristics prior to and after remelting of a $\mathrm{B}_{4} \mathrm{C}$ particle-reinforced AMC. The results indicate comparable mechanical properties of the recycled and the initial composite proofing applicability of remelting processes for recycling [5].

Shishkin et al. investigated the disintegration of a boron-tungsten fiber-reinforced AMC using milling to break down the composite to fragments as a first step of recycling. As an outcome, relations between the milling energy and the resulting size of the fragments are derived [6].

Di Ilio and Paoletti focused on machinability aspects of MMCs. Efforts concerning the improvement of castability and formability of MMCs are pointed out enabling enhanced near-net shape manufacturing. It is indicated that finishing by machining is necessary to meet the part requirements [7].

\subsection{Cutting Materials for AMC Machining}

Machining of AMCs with ceramic particles leads to an increased tool wear due to abrasion compared to unreinforced alloys. The reinforcements provide hardness values higher than those of conventional cutting tool materials resulting in an inappropriate wear behavior when machining MMCs.

Hung et al. investigated the tool performance in turning of AMCs based on cast and powder metallurgically produced wrought alloys reinforced with 20 vol. $\%$ of $\mathrm{SiC}$ particles with an average particle size of $13 \mu \mathrm{m}$. The investigated cutting materials comprised high-speed steels (HSS), uncoated and coated cemented carbides, cubic boron nitride (CBN), and polycrystalline diamond (PCD). Applying similar cutting speeds, HSS and cemented carbides reached the tool life criterion significantly earlier compared to the super hard cutting materials. The highest wear resistance is provided using PCD-tipped tools for both investigated AMCs [8].

Yanming and Zehua investigated turning of a $15 \mathrm{wt} . \% \mathrm{SiC}$ particle-reinforced aluminum cast alloy A356 using HSS, uncoated and coated cemented carbides, cutting ceramics, CBN, and PCD. The results indicate that cutting materials with higher hardness compared to the SiC particles are required especially when machining AMCs with higher average particles sizes. Conventional cutting materials are potentially applicable for AMCs reinforced with small particles [9].

Ding et al. examined the tool performance when turning a $20 \mathrm{vol} \% \mathrm{SiC}$ particle-reinforced aluminum cast alloy focusing on super hard cutting materials such as polycrystalline CBN grades, both commercially available and experimental as well as PCD. The findings show that the application 
of PCD is more appropriate compared to the investigated CBN grades (Figure 1). PCD provides higher hardness values than $\mathrm{CBN}$, thus enhancing resistance against abrasion, while reducing the tendency for built-up edge formation [10].

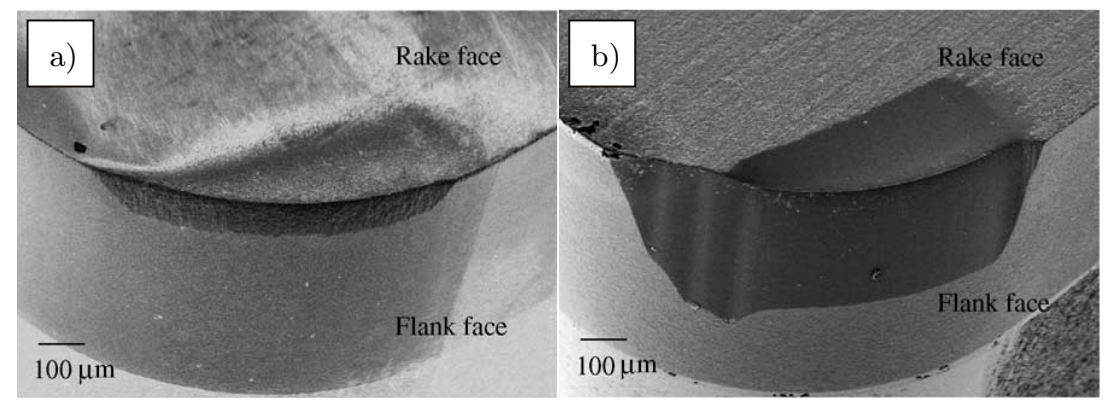

Figure 1. Comparison of tool wear (a) PCD-tipped and (b) IZ900 CBN-tipped tool according to [10].

Bushlya et al. investigated different commercially available and experimental PCD and CBN grades when machining a 20 vol. $\% \mathrm{SiC}$ particle-reinforced aluminum cast alloy with average particle sizes of $10 \mu \mathrm{m}$ to $30 \mu \mathrm{m}$. The findings indicate that experimental PCD grades with a diamond particle fraction of $60 \mathrm{vol} . \%$ or $95 \mathrm{vol} . \%$ perform worse compared to experimental CBN cutting materials. Eventually, the results show the highest wear resistance with a PCD grade based on cobalt binder, outperforming PCD using SiC as binder [11].

Accordingly, the further discussion of the state of the art is focused on different diamond materials suitable for cutting applications.

Wang et al. investigated the machining of an aluminum wrought alloy reinforced with $65 \mathrm{vol} . \%$ of $\mathrm{SiC}$ particles using PCD-tipped tools. For the experiments PCD grades with average diamond particle sizes of $1 \mu \mathrm{m}, 10 \mu \mathrm{m}$, and $25 \mu \mathrm{m}$ were applied. The outcome shows that the PCD grade with small particles performs worst, characterized by unsteady tool wear progression. Increased particle sizes enhance abrasion and wear resistance, but lead to vibrations applying the PCD grade with the largest particle size, as coarser particles are separated from the binder more easily. The medium particle-sized PCD grade performs best in the investigated range leading to considerations of bi-modal grain sizes for further investigations [12].

Collins and Cook investigated the tool wear when turning a 20 vol.\% SiC particle-reinforced aluminum wrought alloy AA2618. Different PCD grades, electrically conductive and non-conductive polycrystalline chemical vapor deposition (CVD) diamond, and monocrystalline diamond (MCD) were applied as cutting materials. Abrasion is the predominant wear mechanism, influenced by the ratio of hardness values between particles and cutting material, while tribo-thermal and tribo-chemical effects are less relevant. Reduced diamond particle size entails increased tool wear, thus MCD performs best for the investigated cutting materials [13].

Cooper et al. investigated the tool wear when machining an aluminum wrought alloy AA2124 reinforced by $25 \mathrm{vol} . \% \mathrm{SiC}$ particles with a size of $3 \mu \mathrm{m}$ or $20 \mu \mathrm{m}$ as well as $40 \mathrm{vol} . \%$ of $3 \mu \mathrm{m}$ sized particles using PCD, polycrystalline and monocrystalline CVD diamond, and natural diamond (ND). Fine-grained PCD shows the lowest tool performance, while polycrystalline CVD diamond and PCD with bi-modal grain size enhance the wear resistance. Machining the $25 \mathrm{vol} . \% \mathrm{SiC}$ particle-reinforced AMCs, no significant wear progression occurs for ND and monocrystalline CVD diamond. However, monocrystalline CVD diamond provides an about $40 \mathrm{~min}$ longer tool life compared to ND when turning the 40 vol. $\%$ particle-reinforced AMC [14]. 


\subsection{Surface Properties in AMC Machining}

In addition to challenges concerning tool wear the reinforcements lead to complex interactions within the cutting process and surface imperfections of the generated surface such as voids and micro cracks. Accordingly, numerous works address the surface microstructure and the physical properties of the generated surface after machining.

Muthukrishnan et al. addressed machining of a $15 \mathrm{wt} . \% \mathrm{SiC}$ particle-reinforced aluminum cast alloy using PCD-tipped tools with a fraction of $92 \mathrm{vol} . \%, 94 \mathrm{vol} . \%$, and $90 \mathrm{vol} . \%$ and sizes of $5 \mu \mathrm{m}$, $25 \mu \mathrm{m}$, and $4 \mu \mathrm{m}$ for the diamond particles. The measured roughness values $R a$ exceed the theoretical values significantly due to the heterogeneous composite microstructure. PCD grades with $94 \mathrm{vol} . \%$ and $90 \mathrm{vol} . \%$ of diamond particles result in lower roughness values applying the highest cutting speed [15].

Bushan et al. investigated turning of a $10 \mathrm{wt} . \% \mathrm{SiC}$ particle-reinforced aluminum wrought alloy AA7075 with PCD-tipped tools addressing the influence of the cutting parameters on the roughness values $R a$. The findings show that reduced roughness values are achieved by increasing the cutting speed while keeping the remaining parameters unchanged. A combination of increased feed and depth of cut applying a constant cutting speed, results in higher roughness values [16].

Ge et al. examined milling of a $20 \mathrm{vol} . \% \mathrm{SiC}$ particle-reinforced aluminum alloy AA2009 using PCD-tipped tools. The generated surfaces featured imperfections such as voids, scales, and scratches as well as an affected microhardness of the surface layer up to a depth of $35 \mu \mathrm{m}$. The microhardness peak value appears in a distance of about $20 \mu \mathrm{m}$ from the generated surface [17].

Wang et al. investigated milling of a $65 \mathrm{vol} . \% \mathrm{SiC}$ particle-reinforced and an unreinforced aluminum wrought alloy AA6063 using PCD-tipped tools. The influence of the cutting speed, the feed per tooth, and the depth of cut were examined evaluating the surface roughness values $R a$ and the residual stress state. An increased feed per tooth results in higher roughness values, while an increased cutting speed benefits decreased $R a$ values. The generated surfaces of the unreinforced alloy are characterized by tensile residual stresses, while the generated surfaces of the AMC exhibit compressive residual stresses enhanced by a low feed per tooth and a medium cutting speed [18].

Dong et al. focused on high-speed milling of a $45 \mathrm{vol} . \% \mathrm{SiC}$ particle-reinforced aluminum alloy with PCD-tipped tools. The influence of the cutting speed and the feed per tooth on the surface properties was primarily considered. The results indicate more pronounced and deeper voids with an increase of cutting speed and feed per tooth. Deep imperfections would result from pulled out particles combined with subsurface voids within the surface layer [19].

Han et al. addressed milling of a $65 \mathrm{vol} . \% \mathrm{SiC}$ particle-reinforced aluminum alloy using PCD-tipped tools with different uniform and mixed diamond grain sizes as well as different cutting edge preparations. The influence of the feed per tooth and the depth of cut on the surface properties were examined. An increase of the feed per tooth results in higher values for $R a$ and a raised number of surface defects, while the trend is reversed in case of an increased depth of cut. The lowest roughness values are achieved with a mixed diamond grain size of $2 \mu \mathrm{m}$ and $30 \mu \mathrm{m}$ applying a sharp cutting edge [20].

Schubert et al. investigated turning of a T4 heat-treated $25 \mathrm{vol} . \% \mathrm{SiC}$ particle-reinforced aluminum wrought alloy AA2124 using polycrystalline CVD diamond-tipped tools. The influence of cutting corner geometry, chip breakers, and different feed values was examined. Accordingly, adapted tool breaker geometries (Figure 2) and wiper geometries facilitate reduced surface roughness values but cannot decrease the number and size of surface imperfections. However, tools featuring small corner radii enable almost flawless generated surfaces, due to increased compressive stresses in the cutting zone [21]. 

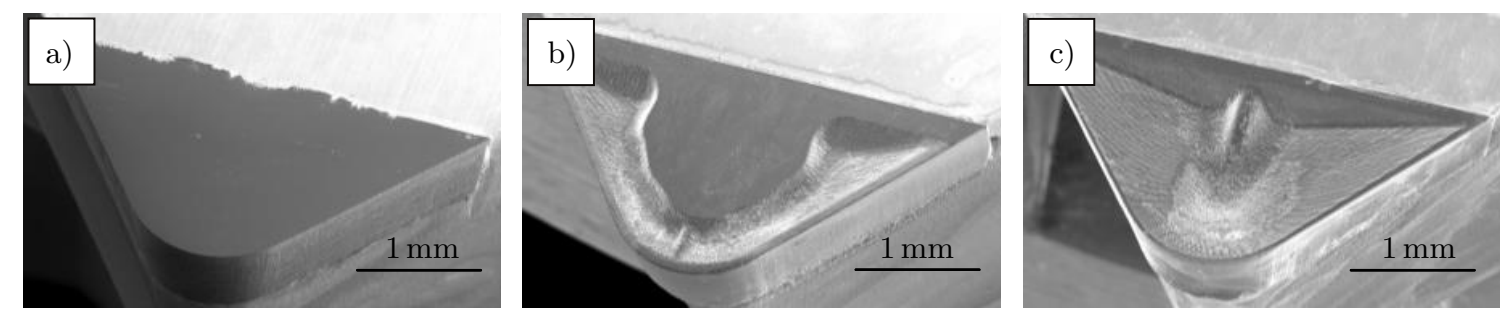

Figure 2. Rake face modifications to enhance machinability (a) Plane rake face (b), (c) different tool breaker geometries according to [21].

Schubert and Nestler addressed modified cutting corner geometries in turning of a $25 \mathrm{vol} . \% \mathrm{SiC}$ particle-reinforced aluminum wrought alloy AA2124 with polycrystalline CVD diamond-tipped tools. The findings indicate that tools with a wiper geometry or trailing edges benefit decreased roughness values $R z$. Moreover, a flank wear of about $100 \mu \mathrm{m}$ led to a decreased number and size of surface imperfections [22].

Clauß, Nestler, and Schubert examined milling of a $10 \mathrm{vol} . \% \mathrm{SiC}$ particle-reinforced powder metallurgically produced aluminum wrought alloy comparable to AA2017 with an average SiC particle diameter below $2 \mu \mathrm{m}$ using polycrystalline CVD diamond-tipped tools. The investigations addressed the influence of the cutting speed and the feed per tooth on the surface structure and the residual stress state. Milling operations with increased cutting speed on average lead to a reduced void formation, while increased values of the feed per tooth result in higher roughness values $R z$ (Figure 3). For low feeds, the theoretical roughness underestimates the measured roughness values, while there is an overestimation with higher feed per tooth. A cutting speed of $200 \mathrm{~m} / \mathrm{min}$ and a feed per tooth of $0.015 \mathrm{~mm}$ result in the strongest compressive residual stresses, significantly higher compared to the initial state [23].

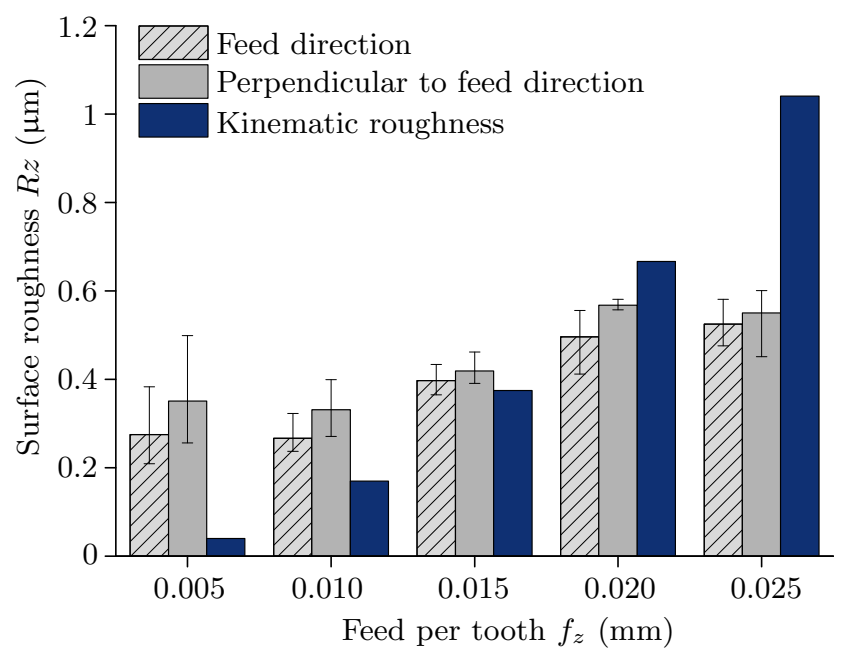

Figure 3. Surface roughness values $R z$ after machining with CVD diamond-tipped tools using different values of the feed per tooth according to [23].

Ge et al. examined ultra-precision turning of 5 vol. $\%, 10 \mathrm{vol} . \%$, and $25 \mathrm{vol} . \% \mathrm{SiC}$ particle-reinforced aluminum cast alloy similar A356 (ZL101A) as well as a $15 \mathrm{vol} \%$ and 25 vol. $\%$ SiC particle-reinforced aluminum wrought alloy AA2024 using MCD- and PCD-tipped tools. Machining with an increased feed leads to higher $R a$ values and more pronounced surface imperfections, yet achieving sub-micrometer roughness values. The thickness of the affected surface layer is higher when using PCD-tipped tools although the highest microhardness increase was achieved with MCD-tipped tools [24]. 
Bian et al. focused on high-precision milling of a $65 \mathrm{vol} . \% \mathrm{SiC}$ particle-reinforced aluminum alloy using MCD-tipped tools. Feed per tooth and depth of cut were varied within a range of several micrometers addressing the transition between brittle and ductile cutting mode. A roughness value $R a$ of $0.078 \mu \mathrm{m}$ is achieved, applying the lowest feed per tooth and the smallest depth of cut. Nonetheless, the generation of imperfections due to particle pull-out and fragmentation cannot be prevented, although some particle separation areas indicate cutting in ductile mode [25].

\subsection{Inferences}

Investigations on milling of SiC particle-reinforced AMCs should be expanded providing a significantly lower number of research activities compared to turning operations. Synthesized monocrystalline diamond cutting materials should be focused with regard to tool wear progression and the influence of a modified tool geometry on the surface properties as indicated by Clauß, Nestler, and Schubert [23]. The experimental investigations should address the surface structure aiming for low roughness values and reduced surface imperfections. Moreover, the examinations ought to contemplate the residual stress state of the generated surface, aiming for high absolute values of compressive residual stresses. Eventually, the microstructure of the surface layer should be assessed to determine the influence of a predefined tool geometry.

\section{Material and Methods}

The experimental investigations are focused on side milling of a particle-reinforced AMC. For the reason of the highly abrasive nature of the ceramic reinforcements the application of MCD as cutting material is beneficial to keep the tool wear in an acceptable range, supporting a controlled and steady wear progression, additionally enabling an appropriate modification of the tool geometry. In the experiments especially the effect of a modified clearance angle $\alpha_{0}^{\prime}$ and rake angle $\gamma_{0}^{\prime}$ of the minor cutting edge is examined.

The single-edged tools (Medidia GmbH, Idar-Oberstein, Germany) have a diameter of $3 \mathrm{~mm}$ and a clearance angle of the minor cutting edge $\alpha_{\mathrm{o}}^{\prime}$ of $1^{\circ}, 2^{\circ}$, or $3^{\circ}$ respectively. The influence of the rake angle of the minor cutting edge $\gamma_{\mathrm{o}}^{\prime}$ is investigated for the values $-5^{\circ}, 0^{\circ}$, and $5^{\circ}$. The cutting edge angle of the minor cutting edge $\kappa_{\mathrm{r}}^{\prime}$ is kept constant at $2^{\circ}$, resulting in a tool included angle $\epsilon_{\mathrm{r}}$ of $88^{\circ}$. The cutting corner features a chamfer of $0.1 \mathrm{~mm} \times 45^{\circ}$ focusing on geometrical stability.

For a better understanding of the tool geometry Figure 4a presents an overview of the cutting part of one of the MCD-tipped tools used, while a more detailed view on the rake face, the cutting corner, and the minor cutting edge is presented according to Figure $4 \mathrm{~b}$. For the experimental investigations one tool of each type with the given specifications is used.

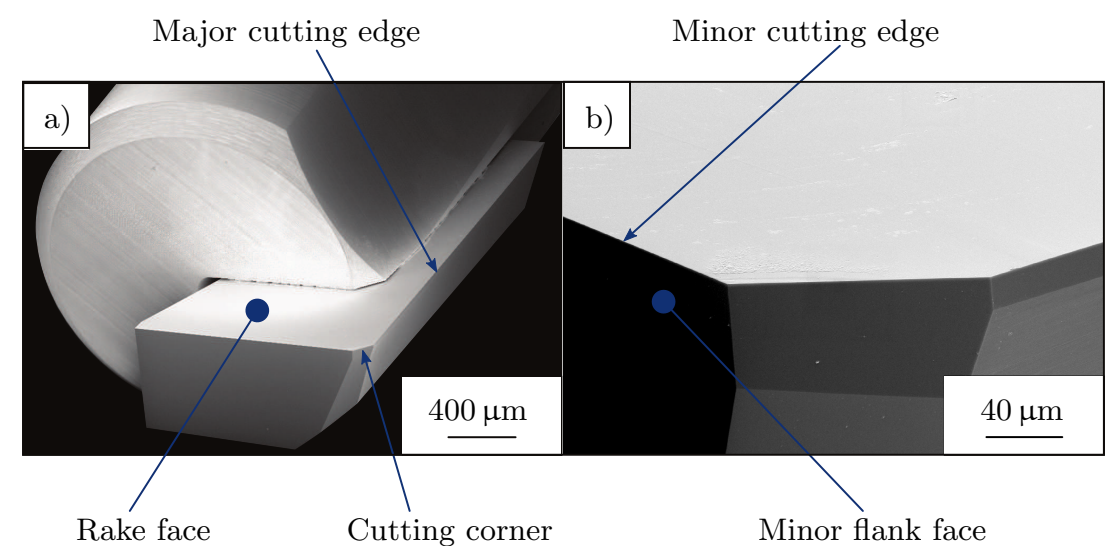

Figure 4. Geometry of an MCD-tipped tool (a) Overview of cutting part and (b) Detailed view on rake face and cutting corner. 
Scanning electron microscopy (SEM) is used subsequent to the cutting experiments to investigate the tool wear of the applied tools. Based on SEM images using a microscope of the type LEO 1455VP (Carl Zeiss Microscopy GmbH, Jena, Germany) the flank wear land width VB was assessed qualitatively.

For the manufacturing of the specimens, an AMC is used, which was developed within the framework of the Collaborative Research Center SFB 692 HALS. Hockauf et al. in detail investigated the fabrication process of the addressed composite material. Accordingly, the matrix consists of an aluminum wrought alloy comparable to the type EN AW-2017 $\left(\mathrm{AlCu}_{3.9} \mathrm{Mg}_{0.7} \mathrm{Mn}_{0.6}\right)$. As reinforcements $\mathrm{SiC}$ particles with a size of $d_{90}<2 \mu \mathrm{m}$ and a proportion of $10 \mathrm{vol} . \%$ are used. Accordingly, $90 \%$ of the particles provide a diameter less than $2 \mu \mathrm{m}$. The composite is produced using a powder metallurgical route. Therefore, all components are mixed in powder state, high energy milled, and pressed hot isostatically. Subsequently, the compacted raw material is extruded to improve the mechanical properties. Eventually, a T4 heat treatment is applied [26].

Table 1 presents the averaged specific values of relevant mechanical parameters determined by tensile tests in the direction of extrusion. Furthermore, hardness measured on an area perpendicular to the direction of extrusion is given.

Table 1. Mechanical properties of the investigated composite.

\begin{tabular}{cc}
\hline Mechanical Parameter & Value \\
\hline Yield strength $R_{\mathrm{p} 0.2}$ & $467 \mathrm{MPa}$ \\
Ultimate tensile strength $R_{\mathrm{m}}$ & $610 \mathrm{MPa}$ \\
Young's modulus $E$ & $90 \mathrm{GPa}$ \\
Fracture elongation $A_{\mathrm{g}}$ & $8.6 \%$ \\
Vickers hardness $H V$ & $182 \mathrm{HV} 10$ \\
\hline
\end{tabular}

Figure 5 presents cross sections showing the microstructure of the AMC in the longitudinal (extrusion) direction and in the cross direction. In general, a comparably homogeneous particle distribution as well as a statistical variation of the particle size are apparent. However, as a side effect of the extrusion process banding effects appear in the longitudinal direction. As a result, the anisotropy of the mechanical properties is increased. Concerning the experimental investigations, the influence of banding on the surface properties is limited, by aligning all surfaces to be machined perpendicular to the extrusion direction.

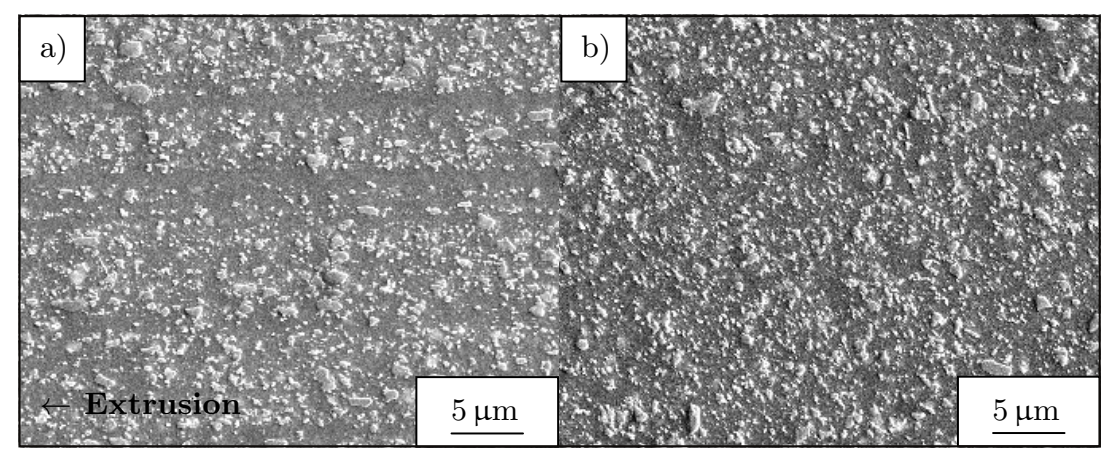

Figure 5. Cross sections of the AMC (a) In the longitudinal direction and (b) In the cross direction.

The side milling tests are carried out using a high-precision milling center of the type KERN Pyramid Nano (KERN Microtechnik GmbH, Eschenlohe, Germany). Flood cooling is applied throughout all experiments using emulsion as cooling lubricant based on Cimstar 501-Cimcool metalworking concentrate (Cimcool Industrial Products B.V., Vlaardingen, The Netherlands). The specimens, represented by cylindrical sections with a diameter of $12 \mathrm{~mm}$ and a length of $10 \mathrm{~mm}$ are clamped 
on a specifically designed device which incorporates a piezoelectric dynamometer of the type Kistler MiniDyn 9256A2 (Kistler Instrumente AG, Winterthur, Germany). Accordingly, in-process acquisition of data concerning the components of the resulting force in milling is enabled. Figure 6 shows the experimental setup for the investigations.

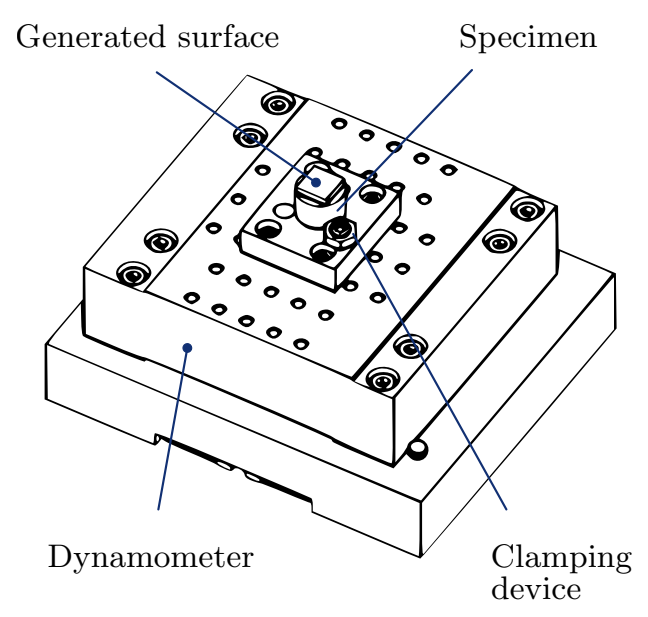

Figure 6. Experimental setup for milling of AMCs.

Figure 7 illustrates the kinematics in side milling, applied for the cutting tests. In a first step, a CVD diamond-tipped auxiliary tool (Diamond Tooling Systems GmbH, Kaiserslautern, Germany) is used to create a square surface of $(9 \times 9) \mathrm{mm}^{2}$ at each specimen to benefit constant cutting conditions. Subsequently, each specimen is machined with the single-edged MCD-tipped tool corresponding to the experimental parameters. In this context, several tool paths according to the width of cut $a_{\mathrm{e}}$ result in the generation of the surface. Moreover, the milling operations are realized in down-milling, typically benefiting chip formation, thus resulting in enhanced surfaces.

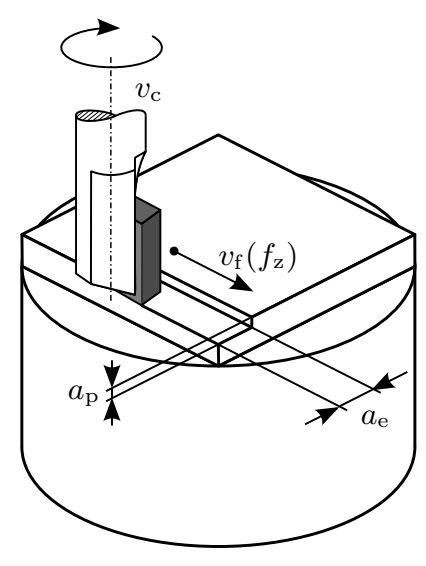

Figure 7. Kinematics in side milling using single-edged tools.

The cutting parameters are kept constant with a cutting speed $v_{\mathrm{c}}$ of $250 \mathrm{~m} / \mathrm{min}$, a feed per tooth $f_{\mathrm{z}}$ of $0.015 \mathrm{~mm}$, a depth of cut $a_{\mathrm{p}}$ of $0.25 \mathrm{~mm}$ and a width of cut $a_{\mathrm{e}}$ of $0.5 \mathrm{~mm}$. Clauß, Nestler, and Schubert already conducted investigations on the influence of the cutting parameters when milling the same SiC particle-reinforced AMC. The investigations were realized using a CVD diamond-tipped double-edged tool [23]. Intending to complement the existing data base and expanding the field of milling AMCs using MCD-tipped tools, the specific values of the cutting parameters are chosen comparable to medium levels of the previous investigations. For enhanced statistical reliability, each combination is realized in three repetitive experiments. The investigated combinations of the cutting parameters and the tool geometry aspects are summarized according to Table 2. 
Table 2. Parameter combinations investigated in the experiments.

\begin{tabular}{cccccc}
\hline$v_{\mathbf{c}}(\mathbf{m} / \mathbf{m i n})$ & $f_{\mathbf{z}}(\mathbf{m m})$ & $a_{\mathbf{p}}(\mathbf{m m})$ & $a_{\mathbf{e}}(\mathbf{m m})$ & $\alpha_{\mathbf{o}}^{\prime}$ & $\gamma_{\mathbf{o}}^{\prime}$ \\
\hline 250 & 0.015 & 0.25 & 0.5 & $1^{\circ}$ & $0^{\circ}$ \\
250 & 0.015 & 0.25 & 0.5 & $2^{\circ}$ & $0^{\circ}$ \\
250 & 0.015 & 0.25 & 0.5 & $3^{\circ}$ & $0^{\circ}$ \\
250 & 0.015 & 0.25 & 0.5 & $2^{\circ}$ & $-5^{\circ}$ \\
250 & 0.015 & 0.25 & 0.5 & $2^{\circ}$ & $5^{\circ}$ \\
\hline
\end{tabular}

The properties of the generated surface are evaluated applying different quantitative and qualitative methods. Regarding that, the roughness values $R z$ in the feed direction as well as the valley void volume $V v v$ for each surface are taken into consideration. The 3D data of the generated surfaces are gathered using an optical laser scanning microscope of the type Keyence VK-9700 (Keyence Corporation, Osaka, Japan). The achieved profile or surface data are subsequently evaluated using the software MountainsMap ${ }^{\circledR}$ (Digital Surf, Besançon, France). In this context, the primary surface is levelled by subtraction-method, clipped to a field of $2 \times 2 \mathrm{~mm}^{2}$ and filtered based on a denoising wavelength $\lambda_{\mathrm{s}}$ of $2.5 \mu \mathrm{m}$. Subsequently, roughness profiles with a measured length of $1.5 \mathrm{~mm}$ and an evaluated length of $1.25 \mathrm{~mm}$ are extracted and filtered using a cut-off wavelength $\lambda_{\mathrm{c}}$ of $0.25 \mathrm{~mm}$. Each generated surface is evaluated referring to three roughness profiles and the areal evaluation of the porosity, represented by the value for $V v v$.

The physical properties of the surfaces are evaluated using X-ray diffraction analysis. Regarding that, the $\sin ^{2} \psi$-method is used, enabling the determination of the residual stress state. As instrument a Discover D8 (Bruker Corporation, Billerica, MA, USA) with an X-ray tube incorporating a cobalt anode is used.

The method is based on measuring the diffraction angle of the lattice structure of the matrix in the machined surface layer. In this context, specifically the crystallographic planes $\{311\}$ are taken into consideration (Figure 8). Comparing the values of the deformed and the undeformed grid parameters of the matrix material, residual stresses can be detected and evaluated. Regarding that, the elastic parameters for the X-ray diffraction are approximated with a Young's modulus of $E=69 \mathrm{GPa}$ and a Poisson's ratio of $v=0.35$. Moreover, the measurements are realized based on a circular measuring field with a diameter of $0.5 \mathrm{~mm}$. However, the stress state of $\mathrm{SiC}$ particles is not respected. Regarding the presented investigations, primarily the first principal residual stress $\sigma_{\mathrm{RS}, \mathrm{I}}$ is determined.

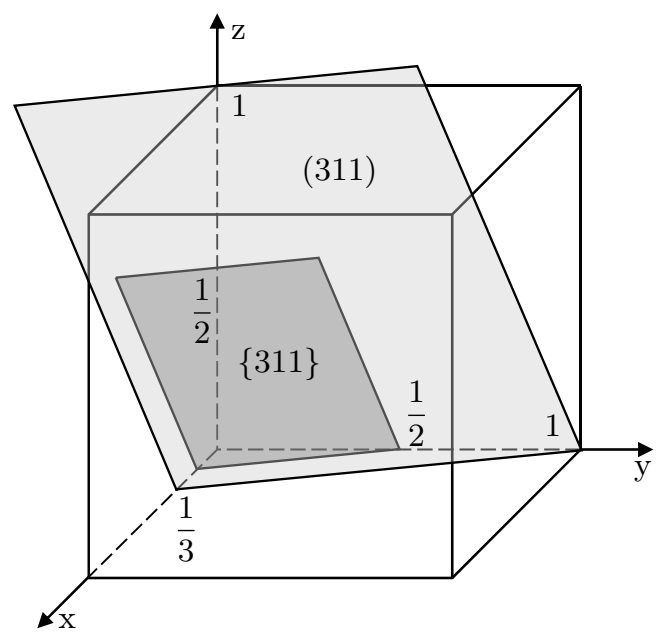

Figure 8. Crystallographic planes $\{311\}$ considered for residual stress evaluation.

The identification of effects of the machining process on the microstructure of the surface layer is achieved by EBSD analysis. The analyses are performed using cross sections, specifically addressing the surface layer of the generated surface as well as the bulk material unaffected by the machining 
process. Regarding that, the achievable result concerning the EBSD pattern quality and thus the base of signals used for evaluation strongly depends on the preparation of the specimens.

In this context, Dietrich et al. described an appropriate preparation method for vibrational polishing with silicon oxide suspension for specimens being subjected to EBSD analysis. It is claimed that an improvement of the EBSD pattern signals can be achieved in contrast to oxide and electro polishing methods. According to experimental investigations comparing the different approaches it is concluded that vibrational polishing compared to the remaining methods enables very levelled and largely undeformed surfaces, thus providing high preparation quality [27]. Consequently, all specimens for EBSD analysis are prepared according to the described method.

Hereafter, the grain size of the aluminum alloy matrix is investigated using the EBSD procedure. The EBSD system itself is integrated into a scanning electron microscope of the type NEON 40EsB (Carl Zeiss Microscopy GmbH, Jena, Germany) which is operated at $15 \mathrm{kV}$ with a $60 \mu \mathrm{m}$ aperture in high current mode. EBSD data sets are measured typically in regions of interest of $(50 \times 80) \mu \mathrm{m}^{2}$ with a sampling size of $100 \mathrm{~nm}$. The $\mathrm{SiC}$ particles appear brighter than the aluminum alloy matrix in secondary electron (SE) images. Accordingly, the SE signal is used to separate the particles from the matrix for filtering the EBSD data sets. Subsequently, the EBSD data are subjected to a slight clean up procedure comprising neighbor confidence index $(\mathrm{CI})$ correlation and grain $\mathrm{CI}$ standardization with a minimum confidence index of 0.1 . The parameters for grain size determination are set to $15^{\circ}$ tolerance angle and a minimum of three hits per grain.

In addition to the quantitative evaluation of the grain size distribution based on the EBSD data sets, a qualitative assessment of the surface layer is realized by inverse pole figure (IPF) color maps. These allow the evaluation and description of the surface layer microstructure, thus providing additional information on grain distribution and characteristics, complementing the quantitative parameters.

\section{Results and Discussion}

The presented research focuses on the influence of the clearance angle $\alpha_{\mathrm{o}}^{\prime}$ and the rake angle $\gamma_{\mathrm{o}}^{\prime}$ of the minor cutting edge on the surface structure, the generation of surface imperfections, and the residual stress state of the generated surface. These properties primarily result from complex interactions between the composite material with its heterogeneous microstructure and the minor cutting edge within the cutting zone.

Subsequently to the experimental investigations the flank wear land width of the used tools was determined in a range of about $10 \mu \mathrm{m}$ to $30 \mu \mathrm{m}$ depending on the specific tool geometry. The strongest flank wear appeared at the tool with a clearance angle of $2^{\circ}$ and a negative rake angle of $-5^{\circ}$. Although providing comparably low values for $V B$ referring to typically applied wear criteria $(V B=0.3 \mathrm{~mm})$, a possible influence of the flank wear cannot be excluded referring to the resulting surface properties.

Figure 9 presents the influence of the clearance angle of the minor cutting edge on the roughness values for $R z$ of the generated surfaces. In this context, the error bars represent the standard deviation calculated in total based on nine separate roughness measurements gathered from three specimens machined with the same process parameters. 


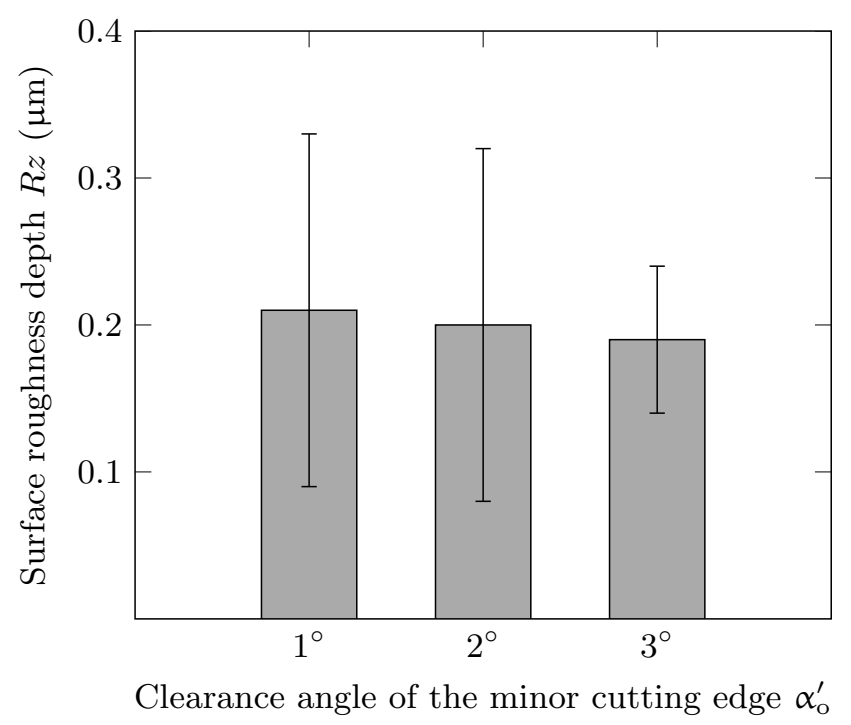

Figure 9. Surface roughness depth $R z$ for different clearance angles $\alpha_{\mathrm{o}}^{\prime}$ of the minor cutting edge $\left(v_{\mathrm{c}}=250 \mathrm{~m} / \mathrm{min}, f_{\mathrm{z}}=0.015 \mathrm{~mm}, a_{\mathrm{p}}=0.25 \mathrm{~mm}, a_{\mathrm{e}}=0.5 \mathrm{~mm}, \gamma_{\mathrm{o}}^{\prime}=0^{\circ}\right)$.

Accordingly, an increase of the clearance angle on average results in a slight yet insignificant decrease of the values for $R z$. The resulting mean values range around $0.2 \mu \mathrm{m}$, with all the generated surfaces featuring a mirror-like surface finish combined with characteristic milling patterns. Moreover, it is evident that especially the application of a clearance angle of $1^{\circ}$ or $2^{\circ}$ results in a stronger fluctuation of the specific values referring to the average roughness values. One reason for that is seen in the comparably low values for $R z$ combined with the complex interactions between the reinforcing particles and the cutting edge. With a decrease of the surface roughness values there is a higher sensitivity towards particle fracture or pull-out. However, even taking the strong fluctuations into consideration any of the investigated tool geometries results in a reliable generation of surfaces with roughness depth values in the sub-micrometer range even below $0.4 \mu \mathrm{m}$. Moreover, despite the quite low average values the use of a clearance angle of $3^{\circ}$ leads to a significantly lower fluctuation. Eventually, taking into consideration both the averaged surface roughness values as well as the fluctuations, the values for $R z$ are comparable for the different clearance angles applied.

Regarding Figure 10 the influence of the rake angle on the surface roughness values of the generated surfaces is presented. Similar to the investigation of different clearance angles the error bars represent the standard deviation taking into account nine separate roughness values.

The results indicate that the rake angle has only minor influence on the achievable surface roughness values. It appears that the highest average value, due to the comparably strong fluctuations results from milling with a clearance angle of $2^{\circ}$ and a rake angle of $0^{\circ}$. Taking only the average values into consideration, no clear trend can be identified increasing the rake angle. The lowest values for $R z$ on average result when using the tool with a clearance angle of $2^{\circ}$ and a positive rake angle of $5^{\circ}$. Respecting the mean values as well as the fluctuations the achieved surface roughness values are in a comparable range. This is mainly attributed to the statistically randomized particle distribution within the composite. Accordingly, highly complex and partially random interactions with the cutting edge occur, even despite comparable cutting conditions. Interestingly, both a negative rake angle as well as a positive rake angle of the minor cutting edge lead to a reduced fluctuation of the roughness values. However, similar to the machining with different clearance angles, in any case the achieved surface roughness $R z$ exhibits values below $0.4 \mu \mathrm{m}$ and a mirror-like surface finish of the generated surface. 


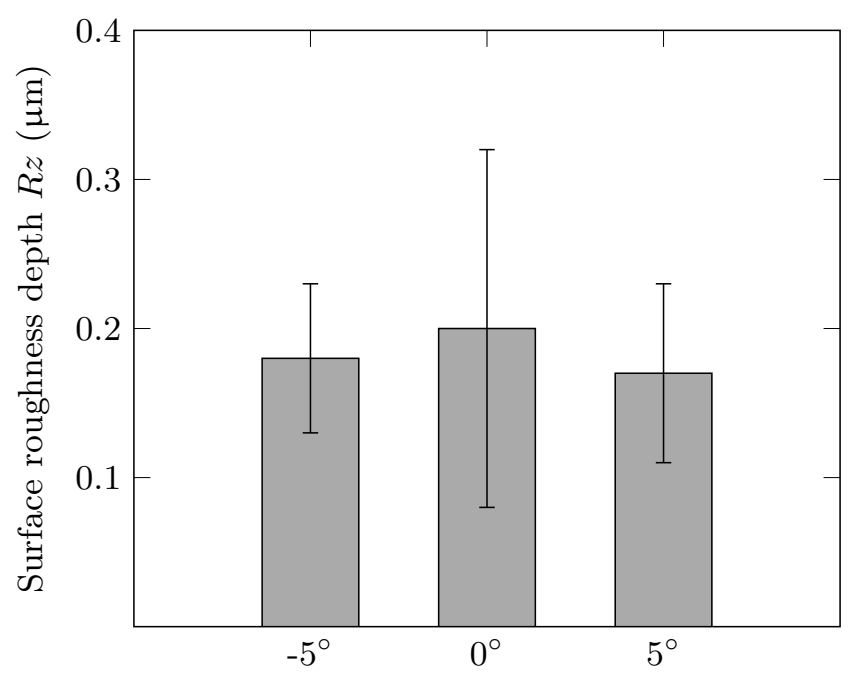

Rake angle of the minor cutting edge $\gamma_{\mathrm{o}}^{\prime}$

Figure 10. Surface roughness depth $R z$ for different rake angles $\gamma_{\mathrm{o}}^{\prime}$ of the minor cutting edge $\left(v_{\mathrm{c}}=250 \mathrm{~m} / \mathrm{min}, f_{\mathrm{z}}=0.015 \mathrm{~mm}, a_{\mathrm{p}}=0.25 \mathrm{~mm}, a_{\mathrm{e}}=0.5 \mathrm{~mm}, \alpha_{\mathrm{o}}^{\prime}=2^{\circ}\right)$.

Figure 11 presents the influence of different clearance angles of the minor cutting edge on the resulting valley void volume $V v v$, representing the porosity of the generated surface. The error bars represent the standard deviation based on the separately evaluated surfaces of the three repetitive experiments for each combination of process parameters.

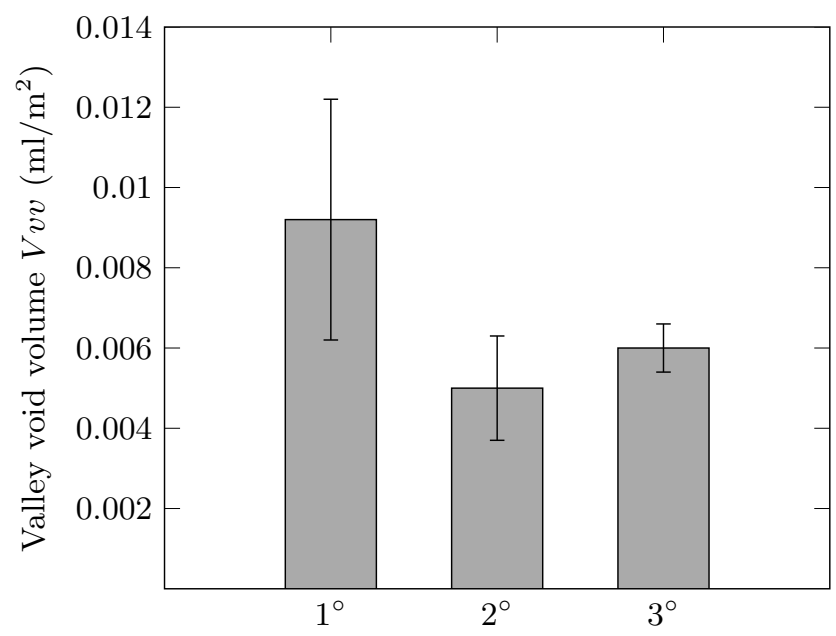

Clearance angle of the minor cutting edge $\alpha_{\mathrm{o}}^{\prime}$

Figure 11. Valley void volume $V v v$ for different clearance angles $\alpha_{\mathrm{o}}^{\prime}$ of the minor cutting edge $\left(v_{\mathrm{C}}=250 \mathrm{~m} / \mathrm{min}, f_{\mathrm{Z}}=0.015 \mathrm{~mm}, a_{\mathrm{p}}=0.25 \mathrm{~mm}, a_{\mathrm{e}}=0.5 \mathrm{~mm}, \gamma_{\mathrm{o}}^{\prime}=0^{\circ}\right)$.

The highest average values result when applying the tool with a clearance angle of $1^{\circ}$ and a rake angle of $0^{\circ}$ of the minor cutting edge. With an increase of the clearance angle up to $2^{\circ}$ the lowest value for $V v v$ is achieved in the investigated range. However, a further increase up to a clearance angle of $3^{\circ}$ leads to higher valley void volumes. While no clear trend is identified concerning the averaged values, the fluctuations can be reduced applying clearance angles of $2^{\circ}$ and $3^{\circ}$ in the investigated range. This is mainly attributed to an interaction of the minor flank face and the generated surfaces in the tertiary cutting zone, intensified by decreased clearance angles.

Figure 12 indicates the influence of the rake angle of the minor cutting edge on the values for $V v v$. The error bars are determined similarly to the investigations for the different clearance angles. 


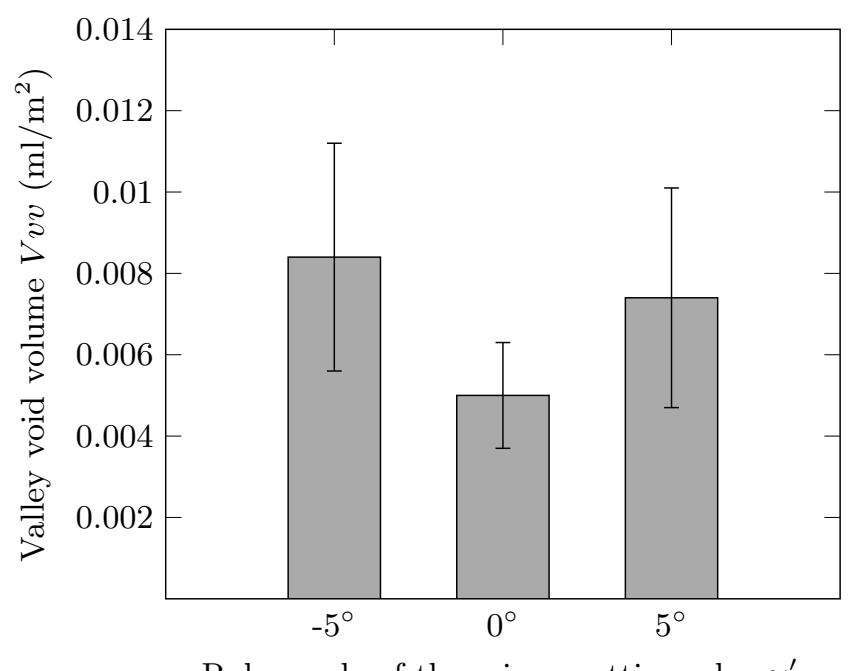

Figure 12. Valley void volume $V v v$ for different rake angles $\gamma_{\mathrm{o}}^{\prime}$ of the minor cutting edge $\left(v_{\mathrm{c}}=250 \mathrm{~m} / \mathrm{min}, f_{\mathrm{z}}=0.015 \mathrm{~mm}, a_{\mathrm{p}}=0.25 \mathrm{~mm}, a_{\mathrm{e}}=0.5 \mathrm{~mm}, \alpha_{\mathrm{o}}^{\prime}=2^{\circ}\right)$.

Accordingly, it emerges that a rake angle of $0^{\circ}$ combined with a clearance angle of $2^{\circ}$ of the minor cutting edge results in the lowest average values for $V v v$ also enabling reduced fluctuations of the specific values compared to the other rake angles applied. In contrast to that, both the negative and the positive rake angle of $-5^{\circ}$ or $5^{\circ}$ result in similar yet significantly higher average valley void volumes compared to a rake angle of $0^{\circ}$. Additionally, there is a considerably higher fluctuation of the specific values in both cases. It is assumed that the findings can be explained with altered stress regimes in the primary shear zone due to different wedge angles, resulting from the variation of the rake angle while keeping the clearance angle constant.

Figure 13 shows the influence of the clearance angle of the minor cutting edge on the resulting residual stress state. The initial stress state within the specimen material after manufacturing and prior to machining was investigated in advance of the cutting experiments. Accordingly, ten separate residual stress measurements evenly distributed over the complete batch of the investigated AMC material were realized. Influences of prior machining operations were removed preparing the measuring field using electro chemical machining (ECM). In this context, the averaged compressive residual stress state of the composite is represented by a dashed line. Moreover, the maximum and minimum values of the measuring sequence are marked with solid lines. On average, there are already initial residual stresses $\sigma_{\mathrm{RS}, \mathrm{I}_{0}}$ of about $-70 \mathrm{MPa}$ within the bulk material fluctuating between $-63 \mathrm{MPa}$ and $-79 \mathrm{MPa}$.

It can be seen that there is only a slight influence of the clearance angle of the minor cutting edge on the residual stress state of the generated surface. However, on average stronger compressive residual stresses are achieved with an increase of the clearance angle from $1^{\circ}$ to $2^{\circ}$, although a further increase results in a reduction of the resulting absolute values of the compressive residual stresses. Taking the averaged values as well as the fluctuations into consideration, comparable values are achieved for the compressive residual stresses, independently of the applied clearance angle. Nonetheless, despite comparably strong fluctuations, in any case the absolute values of the compressive residual stresses are increased compared to the initial stress state.

Figure 14 depicts the influence of the rake angle of the minor cutting edge on the residual stress state of the generated surface. 


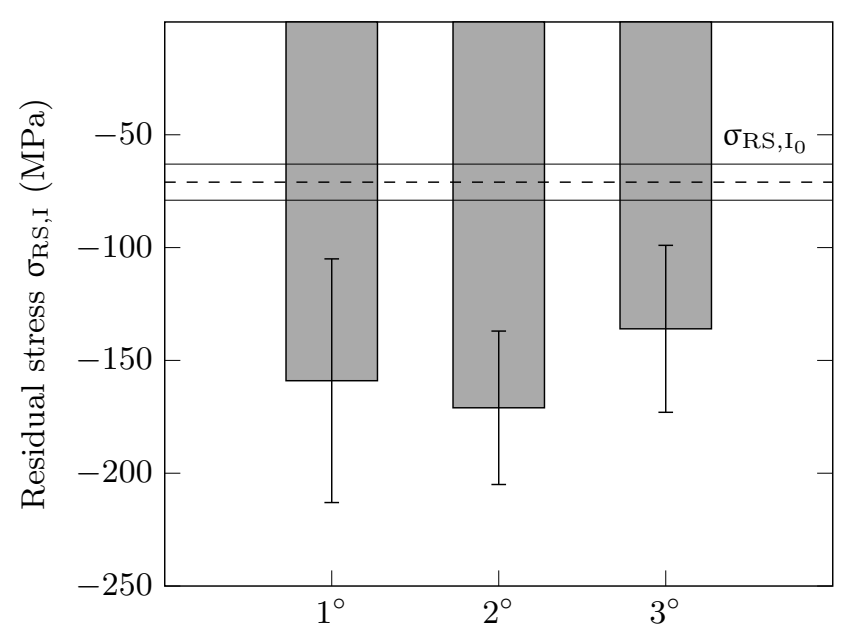

Clearance angle of the minor cutting edge $\alpha_{\mathrm{o}}^{\prime}$

Figure 13. Residual stress $\sigma_{\mathrm{RS}, \mathrm{I}}$ for different clearance angles $\alpha_{\mathrm{o}}^{\prime}$ of the minor cutting edge $\left(v_{\mathrm{c}}=250 \mathrm{~m} / \mathrm{min}, f_{\mathrm{z}}=0.015 \mathrm{~mm}, a_{\mathrm{p}}=0.25 \mathrm{~mm}, a_{\mathrm{e}}=0.5 \mathrm{~mm}, \gamma_{\mathrm{o}}^{\prime}=0^{\circ}\right)$.

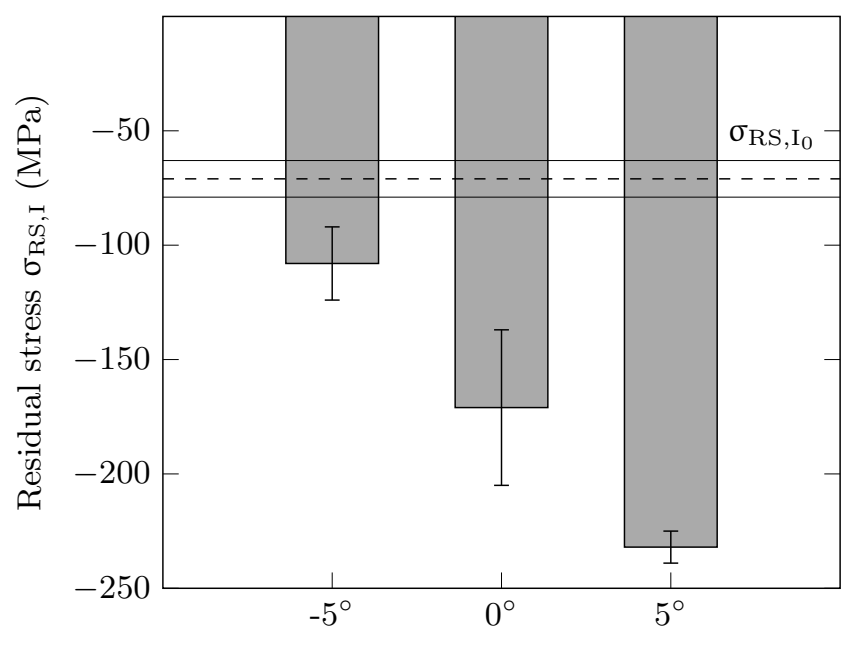

Rake angle of the minor cutting edge $\gamma_{\mathrm{o}}^{\prime}$

Figure 14. Residual stress $\sigma_{R S, I}$ for different rake angles $\gamma_{\mathrm{o}}^{\prime}$ of the minor cutting edge $\left(v_{\mathrm{c}}=250 \mathrm{~m} / \mathrm{min}\right.$, $f_{\mathrm{z}}=0.015 \mathrm{~mm}, a_{\mathrm{p}}=0.25 \mathrm{~mm}, a_{\mathrm{e}}=0.5 \mathrm{~mm}, \alpha_{\mathrm{o}}^{\prime}=2^{\circ}$ ).

The results indicate that milling with a tool featuring a positive rake angle of the minor cutting edge of $5^{\circ}$ leads to stronger compressive residual stresses compared to a negative and a neutral rake angle of $-5^{\circ}$ or $0^{\circ}$, respectively. Moreover, it can be derived that the use of a negative as well as a positive rake angle results in a reduced fluctuation of the generated compressive residual stresses. However, even taking into consideration the comparably strong fluctuations when machining with a rake angle of $0^{\circ}$, the highest absolute values of the compressive residual stresses in the investigated range are evidently achieved with the tool comprising a positive rake angle. On average the highest achieved compressive residual stresses provide values of about $-230 \mathrm{MPa}$, thus increasing the absolute value of the initial residual stress state up to about $290 \%$. The results are primarily attributed to the different wedge angles resulting from the rake angle variation while keeping the clearance angle constant. As a result, contrary mechanical and thermal effects appear in the primary shear zone. On the one hand it is known that the residual stress state results from lattice deformations of the matrix material. These can be promoted by increased plastic deformation typically combined with an increase of the passive force component and a refinement of the surface layer microstructure. On the other hand, with a larger extent of plastic deformation in the cutting zone the internal friction within the microstructure increases as well, resulting in higher cutting temperatures. Consequently, initialized 
recrystallization effects, reduction of lattice deformation, and thus the degradation of residual stresses is assumed to be benefited.

Comparing the presented results, especially concerning the residual stress state with the findings of Clauß, Nestler, and Schubert [23], interesting aspects can be derived with reference to the effects of different diamond cutting materials on the surface properties when machining AMCs. The milling of an identically composed $\mathrm{SiC}$ particle-reinforced AMC was investigated using double-edged CVD diamond-tipped tools and comparable cutting parameters. However, the achieved absolute values of the compressive residual stresses up to $-141 \mathrm{MPa}$ in most cases were lower compared to the compressive residual stress generated with MCD-tipped tools. This is primarily attributed to the differences of the cutting materials applied. In contrast to the MCD-tipped tools used in the presented investigations the CVD diamond grade applied by Clauß, Nestler, and Schubert [23] features a polycrystalline structure. Accordingly, when using MCD as cutting material significantly lower cutting edge radii are achievable, resulting in a changed stress concentration within the cutting zone, evidently leading to increased compressive residual stresses of the generated surface. Furthermore, the heat conduction in diamond is based on oscillation, affected by the structural properties of the diamond material. Consequently, it is reasonable to assume that the typically polycrystalline CVD diamond cutting grades provide a lower thermal conductivity compared to MCD. Accordingly, when using MCD-tipped tools it can be stated that the influence of thermal effects as a result of the cutting process can be reduced as well.

Figure 15 constitutes the grain size distribution within the surface layer machined with a rake angle of $-5^{\circ}$. The characterization is based on the EBSD data sets determining the assigned grain size distribution according to histogram analysis.

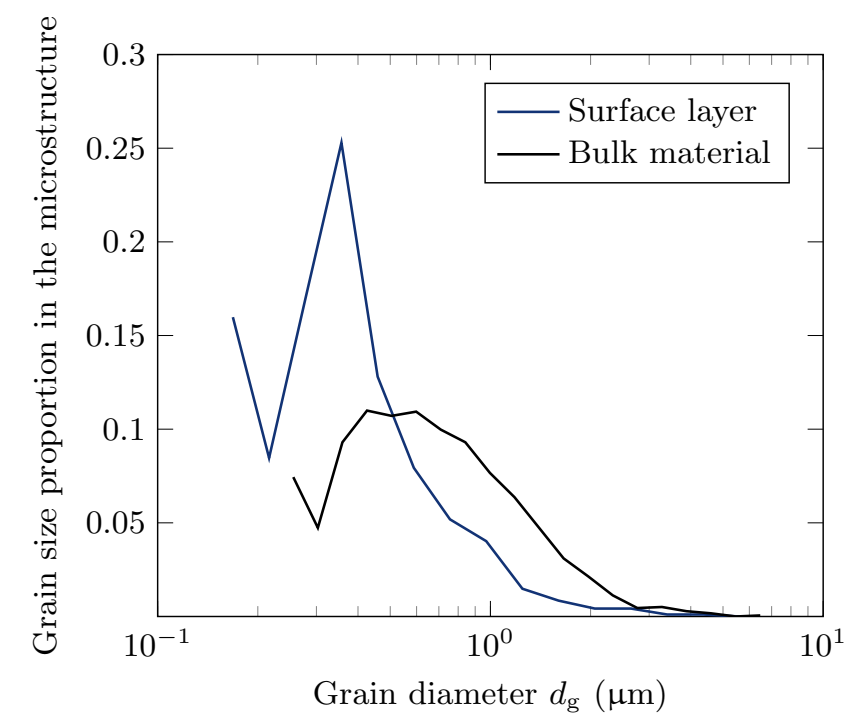

Figure 15. Grain diameter distribution in the bulk material and the surface layer for $\mathrm{a}-5^{\circ}$ rake angle $\gamma_{\mathrm{o}}^{\prime}$ of the minor cutting edge $\left(v_{\mathrm{c}}=250 \mathrm{~m} / \mathrm{min}, f_{\mathrm{z}}=0.015 \mathrm{~mm}, a_{\mathrm{p}}=0.25 \mathrm{~mm}, a_{\mathrm{e}}=0.5 \mathrm{~mm}, \alpha_{\mathrm{o}}^{\prime}=2^{\circ}\right)$.

Taking the different plots into consideration, it can be concluded that the machining process typically leads to a larger proportion of finer grains compared to the microstructure of the bulk material. Accordingly, a strong effect is identified as a result of machining with the tool featuring a rake angle of $-5^{\circ}$ of the minor cutting edge. Compared to the unaffected bulk material, the microstructure of the surface layer provides a strongly increased fraction of fine grains with a peak in the range between $0.3 \mu \mathrm{m}$ and $0.4 \mu \mathrm{m}$.

Figure 16 presents the grain size distribution within the surface layer generated with a rake angle of $5^{\circ}$. 


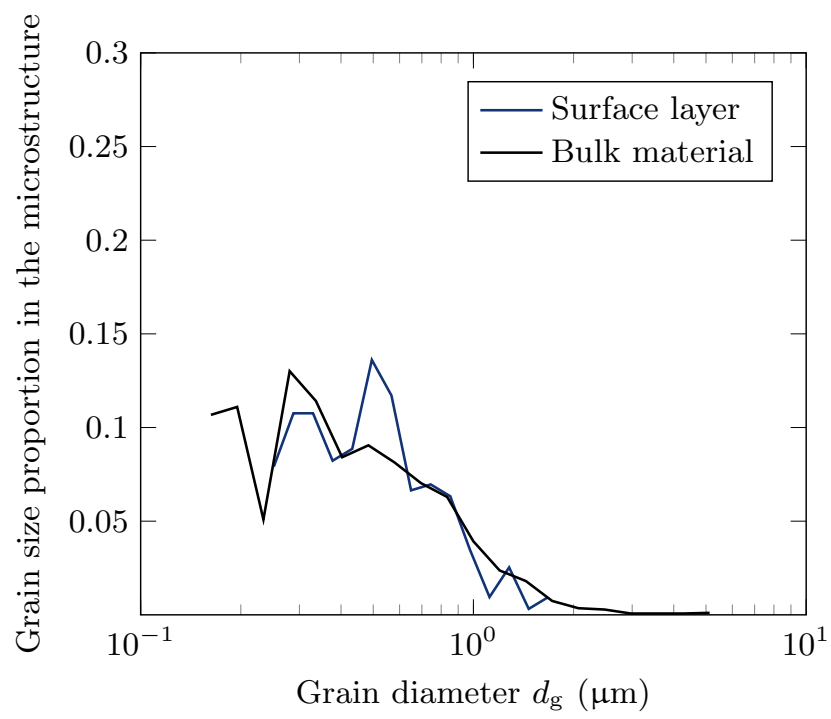

Figure 16. Grain diameter distribution in the bulk material and the surface layer for a $5^{\circ}$ rake angle $\gamma_{\mathrm{o}}^{\prime}$ of the minor cutting edge $\left(v_{\mathrm{c}}=250 \mathrm{~m} / \mathrm{min}, f_{\mathrm{z}}=0.015 \mathrm{~mm}, a_{\mathrm{p}}=0.25 \mathrm{~mm}, a_{\mathrm{e}}=0.5 \mathrm{~mm}, \alpha_{\mathrm{o}}^{\prime}=2^{\circ}\right)$.

In contrast, the microstructure of the surface layer significantly distinguishes from the textural pattern generated with a rake angle of $-5^{\circ}$. The resulting peak values are found in two different ranges with maxima around $0.3 \mu \mathrm{m}$ and $0.5 \mu \mathrm{m}$ each exhibiting a lower grain fraction in the microstructure compared to the maxima when using a tool with a rake angle of $-5^{\circ}$.

Although the assessment of the grain size distribution allows a quantification of the surface layer microstructure in terms of grain size fractions, it does not provide qualitative information on the composition of the microstructure near the generated surface. In this context, the IPF approach complementary allows the visual assessment of the microstructural composition in the surface layer combined with the grain sizes and distributions as well as the description of the crystallographic orientation of the single grains. Regarding that, the aluminum grains of the matrix alloy are presented in different colors according to the crystallographic orientation, the black areas represent SiC particles.

Figure 17 presents the surface as a result of machining with a rake angle of $-5^{\circ}$ and a clearance angle of $2^{\circ}$.

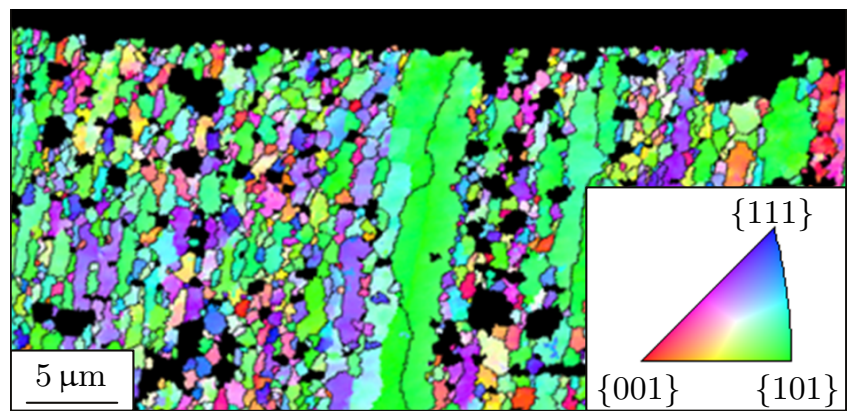

Figure 17. Microstructure of the surface layer for a $-5^{\circ}$ rake angle of the minor cutting edge $\left(v_{\mathrm{c}}=250 \mathrm{~m} / \mathrm{min}, f_{\mathrm{z}}=0.015 \mathrm{~mm}, a_{\mathrm{p}}=0.25 \mathrm{~mm}, a_{\mathrm{e}}=0.5 \mathrm{~mm}, \alpha_{\mathrm{o}}^{\prime}=2^{\circ}\right)$.

Figure 15 indicates that machining with a rake angle of $-5^{\circ}$ leads to the most significant change of the microstructure in terms of the dominant grain size fraction. However, based on the associated IPF image (Figure 17) the distribution appears comparably homogeneous with a slight increase of the proportion of fine grains towards the surface. In contrast to that, the transformation of the overall microstructural composition according to Figure 16 appears less significant. Furthermore, the plot is characterized by two specific values of grain diameter providing local maxima, in contrast to one dominating maximum with Figure 15. Nonetheless, the related IPF image according to Figure 18 
constitutes a strongly distinguished composition of the surface layer, when applying a tool with a rake angle of $5^{\circ}$.

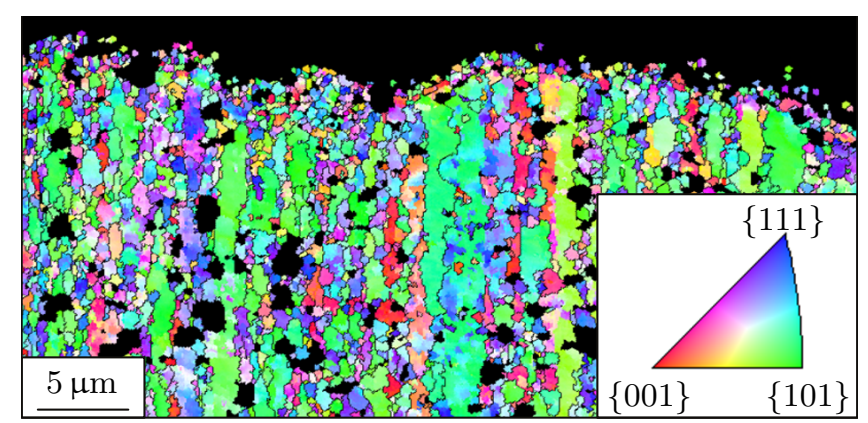

Figure 18. Microstructure of the surface layer for a $5^{\circ}$ rake angle of the minor cutting edge $\left(v_{\mathrm{c}}=250 \mathrm{~m} / \mathrm{min}, f_{\mathrm{z}}=0.015 \mathrm{~mm}, a_{\mathrm{p}}=0.25 \mathrm{~mm}, a_{\mathrm{e}}=0.5 \mathrm{~mm}, \alpha_{\mathrm{o}}^{\prime}=2^{\circ}\right)$.

The dominating grain sizes and distributions of particles in a distance of about $5 \mu \mathrm{m}$ to $10 \mu \mathrm{m}$ from the generated surface appear comparable when applying tools with a rake angle of $-5^{\circ}$ or $5^{\circ}$, respectively. However, in contrast to the surface generated with a negative rake angle, the surface resulting from machining with a positive rake angle exhibits a distinctly formed band of fine-grained particles representing the generated surface. Moreover, stronger irregularities can be found in case of applying a positive rake with some grains appearing to be disconnected from the surface layer. This is primarily attributed to increased challenges, especially when detecting single grains with strongly reduced sizes. Eventually, a stronger deformation of the surface layer is observed compared to the surface layer produced with a rake angle of $-5^{\circ}$. In this context, milling with the tool featuring a positive rake angle of $5^{\circ}$ leads to the strongest compressive residual stresses in the investigated range according to Figure 14. The EBSD analyses require the preparation of a cross section of the examined specimen that can lead to outbreaks in the transition area between the surface and the embedding material, particularly with high compressive residual stresses. Moreover, the equilibrium conditions prior to preparation are affected, influencing the degradation of the residual stresses and the deformation within the surface layer. However, the IPF image indicates a fine-grained affected surface layer with a thickness of at least $1 \mu \mathrm{m}$ to $2 \mu \mathrm{m}$ as a result of the cutting process.

\section{Summary and Conclusions}

Based on a fractional experimental design, investigations concerning milling of a particlereinforced AMC are realized. The composite used consists of an aluminum wrought alloy similar to EN AW-2017 reinforced with 10 vol.\% of SiC particles. For the cutting tests MCD-tipped single-edged tools are applied. The cutting experiments particularly address the influence of the clearance angle $\alpha_{\mathrm{o}}^{\prime}$ and the rake angle $\gamma_{\mathrm{o}}^{\prime}$ of the minor cutting edge on the properties of the generated surface.

Regarding that, the achieved roughness values for $R z$, the porosity represented by the valley void volume $V v v$, and the residual stress state, especially the first principal residual stress $\sigma_{R S, I}$ are taken into consideration. The values for roughness and porosity are evaluated using optical surface data gathered with a confocal laser scanning microscope. The residual stresses are determined based on X-ray diffraction analysis according to $\sin ^{2} \psi$-method. Additionally, EBSD analyses are realized to characterize the microstructure of the surface layer.

According to the achieved results an increase of the clearance angle of the minor cutting edge up to $3^{\circ}$ leads to a slight reduction of the average surface roughness values $R z$ combined with decreased fluctuations of the specific values. A decreased average valley void volume, thus representing reduced porosity is achieved by applying a rake angle of $0^{\circ}$ as well as a clearance angle of $2^{\circ}$. Moreover, strong effects of a varied rake angle influencing the residual stress state are identified. In this context, a positive rake angle of the minor cutting edge of $5^{\circ}$ leads to the strongest compressive residual stresses in the investigated range. Compared to the initial state of the bulk material the absolute values of the 
compressive residual stresses are increased up to about $290 \%$. However, the surfaces generated by milling exhibit stronger compressive residual stresses for any used tool compared to the initial state. Concerning the microstructure of the generated surface, a positive rake angle involves a fine-grained surface layer with thickness values of at least $1 \mu \mathrm{m}$ to $2 \mu \mathrm{m}$.

The presented investigations provide an enhanced insight into the relation between the machining process and the resulting surface properties when milling particle-reinforced AMCs with MCD-tipped tools. The adaptation of the tool geometry is identified as promising approach for the generation of surfaces with predefined properties. Moreover, the concept of more comprehensive correlations, respecting surface microstructure, physical properties, and the microstructural characteristics of the surface layer is introduced. However, ongoing research should further focus on an expansion of the in-depth understanding of the mechanisms leading to the determined surface properties.

Author Contributions: Conceptualization, B.C., A.N., A.S. and T.L.; Data curation, B.C.; Formal analysis, B.C.; Investigation, B.C. and D.D.; Project administration, A.S. and T.L.; Resources, A.S. and T.L.; Visualization, B.C.; Writing—original draft, B.C.; Writing-review \& editing, A.N., A.S. and T.L.

Funding: This research was funded by the German Research Foundation (Deutsche Forschungsgemeinschaft DFG, grant number 14208545).

Acknowledgments: The authors gratefully acknowledge funding by the German Research Foundation (Deutsche Forschungsgemeinschaft, DFG) within the framework of the Collaborative Research Center SFB 692.

Conflicts of Interest: The authors declare no conflict of interest. The funders had no role in the design of the study; in the collection, analyses, or interpretation of data; in the writing of the manuscript, or in the decision to publish the results.

\section{Abbreviations}

The following abbreviations and symbols are used in this manuscript:

$\begin{array}{ll}\text { Symbol } & \text { Definition } \\ a_{\mathrm{e}} & \text { Width of cut } \\ a_{\mathrm{p}} & \text { Depth of cut } \\ A_{\mathrm{g}} & \text { Fracture elongation } \\ \mathrm{AMC} & \text { Aluminum matrix composite } \\ \mathrm{CBN} & \text { Cubic boron nitride } \\ \mathrm{CI} & \text { Confidence index } \\ \mathrm{CVD} & \text { Chemical vapor deposition } \\ d_{90} & \text { Particle size } \\ E & \text { Young's modulus } \\ \mathrm{EBSD} & \text { Electron backscatter diffraction } \\ \mathrm{ECM} & \text { Electro chemical machining } \\ f_{\mathrm{z}} & \text { Feed per tooth } \\ \mathrm{HSS} & \text { High-speed steel } \\ H V 10 & \text { Vickers hardness } \\ \mathrm{IPF} & \text { Inverse pole figure } \\ \mathrm{MCD} & \text { Monocrystalline diamond } \\ \mathrm{MMC} & \text { Metal matrix composite } \\ \mathrm{ND} & \text { Natural diamond } \\ \mathrm{PCD} & \text { Polycrystalline diamond } \\ R_{\mathrm{m}} & \text { Ultimate tensile strength } \\ R_{\mathrm{p} 0.2} & \text { Yield strength } \\ R z & \text { Surface roughness depth } \\ \mathrm{SE} & \text { Secondary electron } \\ \mathrm{SEM} & \text { Scanning electron microscopy } \\ & \end{array}$


$v_{\mathrm{C}} \quad$ Cutting speed

$V B \quad$ Flank wear land width

Vvv Valley void volume

$\alpha_{\mathrm{o}}^{\prime} \quad$ Clearance angle of the minor cutting edge

$\gamma_{\mathrm{o}}^{\prime} \quad$ Rake angle of the minor cutting edge

$\epsilon_{\mathrm{r}} \quad$ Tool included angle

$\kappa_{r}^{\prime} \quad$ Tool cutting edge angle of the minor cutting edge

$\lambda_{\mathrm{C}} \quad$ Cut-off wavelength

$\lambda_{\mathrm{s}} \quad$ Denoising wavelength

$v \quad$ Poisson's ratio

$\sigma_{\mathrm{RS}, \mathrm{I}} \quad$ First principal residual stress

$\sigma_{\mathrm{RS}, \mathrm{I}_{0}} \quad$ Initial residual stress

\section{References}

1. Kainer, K.U. Metal Matrix Composites, Custom-made Materials for Automotive and Aerospace Engineering. In Chapter 1: Basics of Metal Matrix Composites; Wiley-VCH: Weinheim, Germany, 2006; pp. 2-3. [CrossRef]

2. Akhil, R. A Study on Recent Trends in the Applications of Metal Matrix Composites. Int. J. Res. Appl. Sci. Eng. Technol. 2018, 6, 172-180.

3. Singh, I.; Chaitanya, S.; Kumar, R. Metal Matrix Composites: Materials, Manufacturing and Engineering. In Chapter 6: Material Removal Processes for Metal Matrix Composites; Davim, J.P., Ed.; De Gruyter: Berlin, Germany, 2014; p. 141.

4. Schmidt, A.; Siebeck, S.; Götze, U.; Wagner, G.; Nestler, D. Particle-Reinforced Aluminium Matrix Composites (AMCs)—Selected Results of an Integrated Technology, User, and Market Analysis and Forecast. Metals 2018, 8, 143. [CrossRef]

5. Guo, Z.; Li, Q.; Shu, G. Evolution of microstructure and mechanical properties of the Al-B ${ }_{4} \mathrm{C}$ composite after recycling. IOP Conf. Ser. Mater. Sci. Eng. 2018, 409, 1-8. [CrossRef]

6. Shishkin, A.; Mironov, V.; Goldjandin, D.; Lapkovsky, V. Recycling of Al-W-B composite material. Key Eng. Mater. 2012, 527, 143-147. doi:10.4028/www.scientific.net/KEM.527.143. [CrossRef]

7. Di Ilio, A.; Paoletti, A. Machining of Metal Matrix Composites. In Chapter 3: Machinability Aspects of Metal Matrix Compoistes; Davim, J.P., Ed.; Springer: London, UK, 2012; p. 63.

8. Hung, N.P.; Boey, F.Y.C.; Khor, K.A.; Oh, C.A.; Lee, H.F. Machinability of cast and powder-formed aluminium alloys reinforced with SiC particles. J. Mater. Process. Technol. 1995, 48, 291-297. [CrossRef]

9. Yanming, Q.; Zehua, Z. Tool wear and its mechanism for cutting SiC particle-reinforced aluminium matrix composites. J. Mater. Process. Technol. 2000, 100, 194-199. [CrossRef]

10. Ding, X.; Liew, W.Y.H.; Liu, X.D. Evaluation of machining performance of MMC with PCBN and PCD tools. Wear 2005, 259, 1225-1234. [CrossRef]

11. Bushlya, V.; Lenrick, L.; Gutnichenko, O.; Petrusha, I.; Oispov, O.; Kristiansson, S.; Stahl, J.E. Performance and wear mechanism of novel superhard diamond and boron nitride based tools in machining Al-SiCp metal matrix composite. Wear 2017, 376-377 Part A, 152-164. [CrossRef]

12. Wang, T.; Xie, L.; Wang, X.; Ding, Z. PCD tool performance in high-speed milling of high volume fraction $\mathrm{SiCp} / \mathrm{Al}$ composites. Int. J. Adv. Manuf. Technol. 2015, 78, 1445-1453. [CrossRef]

13. Collins, J.L.; Cook, M.W. Machining MMCs with Diamond Tools. In Proceedings of the Tribology 2000-Plus, 12th International Colloquium, Ostfildern, Germany, 11-13 January 2000; Volume 3, pp. 1837-1853.

14. Cooper, N.; Pretorius, N.; Bowler, J.; Perkins, N. Machining of metal matrix composites using PCD, natural diamond, single crystal CVD and Polycrystalline CVD diamond. Ind. Diam. Rev. 2007, 3, 34-38.

15. Muthukrishnan, N.; Murugan, M.; Rao, K.P. An investigation on the Machinability of Al-SiC metal matrix composites using pcd inserts. Int. J. Adv. Manuf. Technol. 2008, 38, 447-454. [CrossRef]

16. Bushan, R.K.; Kumar, S.; Das, S. Effect of machining parameters on surface roughness and tool wear of 7075 Al alloy SiC composite. Int. J. Adv. Manuf. Technol. 2010, 50, 459-469. [CrossRef]

17. Ge, Y.; Xu, J.; Fu, Y. Experimental study on high-speed milling of SiCp/Al composites. Adv. Mater. Res. 2011, 291-294, 725-731. [CrossRef]

18. Wang, T.; Xie, L.J.; Wang, X.B.; Jiao, L.; Shen, J.W.; Xu, H.; Nie, F.M. Surface Integrity of High Speed Milling of $\mathrm{Al} / \mathrm{SiC} / 65 \mathrm{p}$ Aluminum Matrix Composites. Procedia CIRP 2013, 8, 475-480. [CrossRef] 
19. Dong, G.; Zhang, Y.; Zhou, M.; Wang, Y. The research of effect of cutting parameters on machined surface defects in high-speed milling of $\mathrm{SiC}_{\mathrm{p}} / \mathrm{Al}$ composites. Key Eng. Mater. 2013, 589-590, 245-251. [CrossRef]

20. Han, J.; Hao, X.; Li, L.; Wu, Q.; He, N. Milling of high volume fraction SiCp/Al composites using PCD tools with different structures of tool edges and grain sizes. Int. J. Adv. Manuf. Technol. 2017, 92, 1875-1882. [CrossRef]

21. Schubert, A.; Nestler, A.; Schmidt, T.; Schneider, J. Finishing of Aluminium Based Light Weight Materials-Influence on Surface Properties. Sustainable production for resource efficiency and ecomobility. In Proceedings of the International Chemnitz Manufacturing Colloquium, Chemnitz, Germany, 29-30 September 2010; pp. 447-464.

22. Schubert, A.; Nestler, A. Enhancement of Surface Integrity in Turning of Particle Reinforced Aluminium Matrix Composites by Tool Design. Procedia Eng. 2011, 19, 300-305. [CrossRef]

23. Clauß, B.; Nestler, A.; Schubert, A. Investigation of Surface Properties in Milling of SiC Particle Reinforced Aluminium Matrix Composites (AMCs). Procedia CIRP 2016, 46, 480-483. [CrossRef]

24. Ge, Y.F.; Xu, J.H.; Yang, H.; Luo, S.B.; Fu, Y.C. Workpiece surface quality when ultra-precision turning of $\mathrm{SiC}_{\mathrm{p}} / \mathrm{Al}$ composites. J. Mater. Process. Technol. 2008, 203, 166-175. [CrossRef]

25. Bian, R.; He, N.; Li, L.; Zhan, Z.B.; Wu, Q.; Shi, Z.Y. Precision milling of high volume fraction $\mathrm{SiC}_{\mathrm{p}} / \mathrm{Al}$ composites with monocrystalline diamond end mill. Int. J. Adv. Manuf. Technol. 2013, 71, 411-419. [CrossRef]

26. Hockauf, M.; Wagner, M.F.X.; Händel, M.; Lampke, T.; Siebeck, S.; Wielage, B. High-strength aluminium-based light-weight materials for safety components-recent progress by microstructural refinement and particle reinforcement. Int. J. Mater. Res. 2012, 103, 3-11. [CrossRef]

27. Dietrich, D.; Berek, H.; Schulze, A.; Scharf, I.; Lampke, T. EBSD and STEM on Aluminum Alloys Subjected to high-degree Plastic Deformation. Pract. Metallogr. 2008, 48, 136-150. [CrossRef]

(C) 2019 by the authors. Licensee MDPI, Basel, Switzerland. This article is an open access article distributed under the terms and conditions of the Creative Commons Attribution (CC BY) license (http:/ / creativecommons.org/licenses/by/4.0/). 